\title{
OS LIVROS DE LEITURA NO FIM DO SÉCULO XIX E INÍCIO DO SÉCULO XX: UMA ANÁLISE DO LIVRO I DA SÉRIE BRAGA E A FORMAÇÃO DO LEITOR LITERÁRIO
}

\author{
SCHOOL READING BOOKS IN LATE 19TH AND EARLY 20TH \\ CENTURIES: AN ANALYSIS OF LIVRO I FROM BRAGA SERIES AND \\ THE LITERARY READER FORMATION
}

Cristiano Camilo LOPES*

\begin{abstract}
Resumo: Neste artigo, tecem-se considerações a respeito do papel que os livros de leitura, bem cultural utilizado no contexto escolar, exerceram na formação de leitores literários no Brasil. As discussões aqui apresentadas voltam-se para uma abordagem histórico-contextual a respeito dos livros de leitura no final do século XIX e na primeira metade do século XX, e toma-se como corpus de análise a obra Livro I da Série Braga. Levando em consideração o corpus analisado neste artigo, sinalizam-se temas que estiveram presentes na educação, tais como: família, escola e pátria. Notemos que, por meio da análise, esses temas são apresentados como mantendo uma interface entre si. Entendemos, na análise, que a família foi vista como um microcosmo do Brasil, e a nação brasileira teve como semente a família no contexto republicano. A escola foi colocada como o elemento intermediário que serviu de extensão da família, e que teve a missão de preparar cidadãos para a república que se formava nas primeiras décadas do século XX. O eixo teórico desta investigação compreende a história da literatura infantil e juvenil brasileira (ARROYO, 2011 COELHO, 2010; LAJOLO, ZILBERMAN, 2010; ZILBERMAN, 2003), e a história da leitura no Brasil (SILVA, 2012; MONARCHA, 2001; LEITE, 2001; PUCCIA, 2003).
\end{abstract}

Palavras-chave: Livros de leitura. Série Braga. Erasmo Braga. Formação do leitor.

Abstract: This paper discusses the role that school reading books, seen as a cultural object in the school context, played in the formation of literary readers in Brazil. Taking Livro I of Braga Series, the discussions focus on a historical-contextual approach regarding reading books at the end of the 19th century and in the first half of the 20th century. Analysis evinced intertwined themes that were present in education such as family, school and nation. Families were seen as a microcosm of Brazil, as it had the family as its seed in the republican context. School was placed as the intermediate element that served as an extension of the family, having the mission of preparing citizens for the republic that was formed in the first decades of the 20th century. The theoretical axis of this investigation comprises history of Brazilian books for young people (ARROYO, 2011; COELHO, 2010; LAJOLO, ZILBERMAN, 2010; ZILBERMNA, 2003) and history of reading books in Brazil (SILVA, 2012; MONARCHA, 2001; LEITE, 2001; PUCCIA, 2003).

Keywords: Reading books. Série Braga. Erasmo Braga. Reader formation.

"Chegamos ao ponto em que temos de educar as pessoas naquilo que ninguém sabia ontem, e prepará-las para aquilo que ninguém sabe ainda, mas que alguns terão que saber amanhã."

Margaret Mead (1968)

\footnotetext{
* Professor da Universidade Presbiteriana Mackenzie (UPM). Doutorado em Letras pela Universidade de São Paulo (USP). E-mail: cristianoclopes@ hotmail.com. ORCID: https://orcid.org/0000-0003-0341-6813.
} 


\section{Introdução: os livros de leitura nas primeiras décadas do século $\mathrm{XX}$}

Ao refletirmos sobre a historiografia da literatura infantil brasileira, percebemos que ela sempre esteve atrelada à escola. O início da literatura infantil no Brasil foi marcado pelo início da organização escolar republicana ainda nos fins do século XIX. Nessa época, configurou-se o cenário para o advento do livro de leitura e o fortalecimento da leitura: obrigatoriedade do ensino para as crianças (1870); ausência de livros de autores brasileiros (os livros eram importados de Portugal); imprensa brasileira; ensino misto; separação do ensino em faixas de idade - a necessidade de livros para cada um desses segmentos; a lista de saberes necessários para cada etapa da formação dos alunos; ensino organizado e conteúdo elaborado.

Nesse cenário, os livros de leitura exerceram um papel singular em relação ao que passou a ser chamado de literatura escolar, afinal foi um bem cultural que "marcou época porque conquistou um lugar próprio no cenário escolar, distinto do ocupado pelos compêndios, pelos livros de lições das matérias do currículo escolar, e porque serviu à educação nacional" (LAGUNA, 2005). São exemplos de autores desse segmento João Köpke, Thomas Galhardo, César Martines, Puiggari-Barreto e Felisberto de Carvalho, Erasmo Braga, entre outros.

O interesse e os esforços por parte do Estado para a implantação de uma escola seriada, com normas, procedimentos, métodos, instalações adequadas para o fim desejado e o incentivo para que intelectuais nacionais produzissem uma literatura para as crianças que começavam a frequentar a escola, entre outros, foram aspectos que marcaram o surgimento da literatura infantil brasileira no contexto do fortalecimento da escola nos fins do século XIX.

Ademais, com a modernização, configuraram-se vários grupos na sociedade que demandaram produtos culturais para si, tais como as donas de casa, as crianças, os trabalhadores, entre outros: "era a República que chegava, trazendo consigo e legitimando a imagem que o Brasil ambicionava agora: a de um país em franca modernização" (LAJOLO; ZILBERMAN, 2010, p. 24). Assim, a produção de bens culturais para os segmentos da sociedade republicana teve um aumento considerável. São exemplos desses bens culturais as revistas e os livros para crianças.

A rápida multiplicação dos livros de leitura no fim do século XIX e nas primeiras décadas do século XX foi impulsionada por uma série de fatores como destacam Oliveira e Souza (2000): “a sua adequação à estrutura do ensino primário. Cada livro correspondia a uma Série e a coleção, de uma mesma autoria, mantinha a continuidade, a coerência e o aprofundamento das lições e dos temas". 
O livro de leitura pode ser considerado "o irmão mais velho do livro didático", pois foi o primeiro recurso para o auxílio dos professores no ensino da leitura e da escrita: "Constituindose no único livro didático permitido nas escolas públicas, o livro de leitura compreendia um objeto cultural e era, ainda, um instrumento de ensino da língua e da leitura e um auxiliar do trabalho docente" (OLIVEIRA; SOUZA, 2000). Ademais, ele acabou se tornando o produto certo para o momento em que foi criado: os assuntos tratados na obra eram escolhidos pelo autor e refletiam os ideais republicanos que tinham na formação escolar um pilar para o projeto da república brasileira. Nesse sentido, Oliveira e Souza (2000) denominam o livro de leitura de "depositário" de conteúdos educacionais que refletiam esses interesses.

Além disso, o mercado editorial viu nesse segmento uma grande oportunidade para a alavancagem na circulação dos livros, por isso, ao analisarmos essas obras, percebemos que se trata também de um produto que foi idealizado, com uma apresentação formal bem trabalhada, com conteúdo organizado em um todo coerente, visando sempre ao público a quem se destinava.

Não houve apenas a demanda de bens culturais para os públicos que surgiam, mas também o surgimento e o fortalecimento de instituições voltadas para os vários públicos que se configuravam.

Nesse sentido, a escola foi a instituição que se tornou responsável pela formação da criança, o que demandou a produção de uma literatura voltada para a criança no ambiente escolar. Então, "começaram a produzir livros infantis que tinham um endereço certo; o corpo discente das escolas igualmente reivindicadas como necessárias à consolidação de um Brasil moderno" (LAJOLO; ZILBERMAN, 2010, p. 28).

A união literatura e escola apresentou aspectos positivos e negativos respectivamente: a escola tanto pôde ser um lugar certeiro para a formação do leitor literário, ou pôde ser um espaço inerte em aguçar a percepção do leitor para o universo ficcional e tudo o que com ele se relaciona.

Nessa relação literatura infantil e escola nos fins do século XIX e início do século XX, os livros de leitura foram "a primeira tentativa de realização de uma literatura infantil brasileira, mostrando que os conceitos 'literatura' e ‘educação' andaram sempre essencialmente ligados” (COELHO, 2010, p. 223). Esse tipo de produção foi o caminho para o ensino da leitura, bem como para outras áreas do conhecimento.

Até então, o ensino da leitura era feito por meio de livros que não eram voltados para o público infantil: 
Um livro de leitura adequado à educação nacional precisaria incluir lições de Geografia e História Pátria, conhecimentos estes básicos para o aprendizado e a prática do "patriotismo esclarecido e previdente". As lições de Geografia deveriam conter "descrições, notícias e ilustrações" e servir como complemento e reforço do livro de classe (o "manual") e do ensino dado pelo professor. Essas noções teriam a tarefa também de recordar as aulas. As lições de História Pátria poderiam apresentar pequenas cenas da história nacional mesmo legendadas, narrações de fatos históricos, biografias dos "homens notáveis", trechos de alguns cronistas com adaptação da linguagem para o entendimento dos leitores e "versos de poetas brasileiros sobre feitos da História Pátria". Com esse procedimento, os alunos, por meio do livro de leitura, aprenderiam bem a História do Brasil. (VERÍSSIMO, 1906, p. 96, 104 e 133-4).

Vemos, assim, que os livros de leitura revelam a cultura em vigor na primeira metade do século XX. Eles servem de um retrato das ideias, normas, práticas, valores, crenças, critérios de avaliação, princípios etc., que tinham primazia no contexto brasileiro nas primeiras décadas do século XX.

Colomer (2007) confirma que, na segunda metade do século XIX, os livros de leitura foram uma solução para o ensino da literatura no ambiente escolar. Entretanto, seu alvo foi sempre a formação moral, e, com isso, podemos afirmar que eles serviram como objeto útil para a aquisição de conhecimentos por meio da leitura.

Os livros de leitura foram seriados para que estivessem de acordo com as etapas do ensino, que também passou a ser sequencial. Além disso, esses livros foram organizados em unidades temáticas de acordo com os assuntos necessários para cada Série, passaram a exercer a função de um manual de formação cognitiva e também moral e cívica, e tornaram-se uma espécie de garantia de que o aluno leu, pelo menos, uma obra ao longo de sua vivência escolar.

Então, a educação literária não foi o alvo dessa produção, pelo contrário, o que se buscou com os livros de leitura foi o ensino da leitura na perspectiva da decodificação e da memorização de datas, lugares, vultos da história ou, ainda, a recitação em voz alta de textos que louvavam a pátria.

Portanto, os livros de leitura funcionaram como um suporte multidisciplinar que tinha como alvo ofertar ao leitor infantil em formação uma narrativa que abarcasse várias áreas do conhecimento. Esse tipo de literatura teve uma circulação significativa na primeira metade do século XX:

[...] pelos numerosos livros aparecidos e utilizados durante a fase que representou no desenvolvimento da literatura infantil brasileira, pode-se afirmar que a literatura escolar, como temos visto, exerceu papel relevante. Não só quanto ao espírito pedagógico propriamente dito em função do seu objetivo didático, mas também revelando e preparando, despertando e cultivando o hábito da leitura entre as crianças da época. (ARROYO, 2010, p. 130). 
Por meio dos livros de leitura produzidos nessa época, podemos fazer uma leitura da infância brasileira, "em particular daquela infância que, frequentando escolas, preparava-se para ser o amanhã deste país que, como então já se dizia, era visto por suas elites como país do futuro" (LAJOLO; ZILBERMAN, 2010, p. 30).

De acordo com Leonardo Arroyo, a temática da infância foi muito debatida nos livros de leitura, pois, nessa época, ainda

[...] considerava-se a criança o adulto menor, sem distinções psicológicas, morfológicas talvez, como também sociais, mas menos filosóficas que entendemos hoje. O menino era o homem em ponto pequeno que deveria progredir dentro dos padrões de moral, sociais e psicológicos válidos para os adultos. (ARROYO, 2010, p. 163-164).

Portanto, a infância que subjaz aos livros de leitura é a concebida pelo adulto voltado para o ideal republicano no início do século XX. Por isso, esses livros, de acordo com Coelho (2010), carregavam os seguintes temas e ideologias: nacionalismo, intelectualismo, tradicionalismo cultural, e moralismo e religiosidade. Este último se expressava pelo caráter exemplar dentro dos preceitos do cristianismo.

Nos ideais presentes nos livros de leitura, percebemos que o conceito de infância apontava para um prisma diferente do que o que a psicologia da infância havia proposto até aquele momento. Então, de um lado, temos os livros de leitura sinalizando os valores políticos e sociais da República, e, de outro lado, encontramos as considerações teóricas da psicologia da infância que se voltaram para o desenvolvimento biopsicológico da criança:

Diferentemente da representação produzida pela psicologia da infância da época presente, sobretudo, nas teorizações sobre métodos de ensino, nos programas escolares e, de forma difusa, na literatura escolar -, que procura caracterizar a "marcha do espírito" da criança, associando crescimento biológico e aptidões de cada ciclo de idade, a imagem da criança segundo os cânones do discurso republicano, elaborado em estilo alto e idealizador, assume, sobretudo, natureza sociológica e política. (MONARCHA, 2001, p. 122).

Puccia (2005, p. 95) acrescenta que "essa educação visava exemplificar comportamentos bons que contribuiriam para um viver e conviver harmonioso em sociedade, além de despertar na criança e no jovem um sentimento de amor, orgulho e pertencimento à terra natal”.

Em uma realidade paralela, contudo, na mesma época dos livros de leitura, Leite (2001) investigou o conceito de infância que subjaz aos livros de viagem produzidos ao longo do século XIX, e o resultado obtido foi que, no corpus analisado, o conceito de infância se configurou mais como um construto social, cultural e histórico mais do que como uma tese da biologia. $\mathrm{E}$ acrescenta: “tendo em mente que a infância não é uma fase biológica da vida, mas uma 
construção cultural e histórica, compreende-se que as abstrações numéricas não podem dar conta de sua variabilidade" (LEITE, 2001, p. 21). Nas considerações do autor, o conceito de infância presente nos livros de viagens esteve mais atrelado aos graus de percepção e intenção de seus autores do que aos elementos fixos da infância de acordo com a perspectiva das ciências humanas.

Por fim, destacamos também que, nesse primeiro esboço de uma literatura nacional, houve a inserção da criança como protagonista nas histórias, o que se mostrou como algo muito significativo do ponto de vista da identificação do leitor com o texto. Entretanto, também é fato que as personagens infantis assumiram uma postura exemplar que evidenciava um alto nível moral e um consequente comportamento exemplar louvável. Isso também fez da literatura um meio para um fim, e não um fim em si mesma.

Feitas estas considerações, cumpre-nos, agora, investigar, por meio da análise literária, de que maneira a Série Braga manifestou essas marcas características dos livros de leitura.

\section{Livro I da Série Braga e a formação do leitor literário}

Erasmo de Carvalho Braga (23/04/1877-11/05/1932) foi um pastor presbiteriano que também atuou como educador e editor. Ele fez seus estudos iniciais na Escola Botucatuense e se formou em Teologia em 1897.

Sua atuação foi ampla e, por meio dela, obteve notoriedade em vários aspectos. Dentre as suas ações, podem-se destacar:

- Magistério no Mackenzie College e no Seminário Presbiteriano em São Paulo (a partir de 1901);

- Docência em grego, hebraico, exegese, literatura oriental, física, química, música, no Seminário Presbiteriano de Campinas;

- Participação na criação da Sociedade Cientifica de São Paulo (1903), da qual foi o primeiro secretário no período entre 1903-1905;

- Membro fundador da Academia Paulista de Letras (1899), juntamente com Benedito Otávio de Oliveira, Alberto Faria, Raul Soares de Moura e Basílio Magalhães;

- Criador da Série Braga (1909), um conjunto de livros de leitura para as quatro primeiras séries da escola; a Série Braga foi publicada por quarenta anos e alcançou mais de cem edições, sendo adotada em muitos estados do Brasil; 
- Integrante da comissão que deu sugestões ao governo brasileiro sobre a reforma educacional (1930);

- Participação na Comissão Brasileira de Cooperação (CBC) da criação da Sociedade para Evangelização dos Índios, mais tarde conhecida como missão Evangélica Caiuá.

Como homenagem a Erasmo Braga, várias escolas do Brasil levam seu nome em reconhecimento ao legado por ele deixado na área da Educação. Dentre elas, destacam-se: Escola Presbiteriana Rev. Erasmo Braga (Dourados/MS); Instituto Erasmo Braga (Mineiros/GO); Instituto Cultural Beneficente Erasmo Braga (Itaperuna/RJ); Escola Estadual Erasmo Braga (Tatuapé/SP); Colégio Estadual Prof. Erasmo Braga (São Gonçalo/RJ).

Com relação à Série Braga (publicada por 40 anos pela Editora Melhoramentos), sabe-se que ela obteve mais de 100 edições e integrou os chamados livros de leitura que vigoraram no Brasil até os anos 1970.

Os livros da Série eram divididos em quatro, sendo um para cada série do primário - Livro I, Livro II, Livro III e Livro IV, e o conteúdo versava sobre a geografia nacional, os vultos da história, educação moral e cívica e lições de escotismo. Esses temas objetivavam oferecer uma boa educação para a formação do bom comportamento nos alunos e, assim, a consequente formação de cidadãos para a vida em sociedade.

Também estão presentes nos livros excertos de textos que integram a literatura universal, e o objetivo de tal inclusão foi a formação do leitor no que concerne à cultura geral. Por isso, encontram-se, nos livros da Série, textos de Alfredo Varela, Olavo Bilac, Coelho Netto, Alberto de Oliveira, Viriato Correia e General Couto de Magalhães. São alguns dos nomes que indicam a preocupação com a formação intelectual dos alunos.

Destacamos também que, a partir de 1938, as edições que se seguiram foram revistas pelo professor Lourenço Filho, que ficou bastante conhecido por sua atuação no movimento dos pioneiros da chamada Escola Nova.

A partir da leitura dos prefácios dos livros da Série Braga, podemos tecer algumas considerações a respeito dos conceitos de literatura e educação literária veiculados nessas obras sob a ótica do autor da Série.

Os Livros I e II da Série apresentam uma proposta de leitura literária e ressaltam a importância da materialidade do livro. Braga entendia que a leitura servia, primordialmente, como auxílio para o professor no letramento do aluno, por isso tratava-se de "[...] uma série 
coordenada e completa para o ensino da leitura" (p. III). Em decorrência disso, o letramento, na perspectiva do autor, possui três objetivos: “educação intelectual, cívica e moral, sem perder de vista os elementos estheticos" (p. III)

Destacamos ainda na questão da leitura que Braga concebia a arte literária como um meio para se cumprirem alguns objetivos da vida social como: "quadros da vida comum, singela e sadia, de indivíduos a quem a economia e um inteligente governo domestico fazem optimistas e felizes" (p. III).

Em relação à materialidade do livro, o autor destacou que o livro, enquanto objeto, deve ser preservado: “[...] a obra tem a seguinte physionomia: technica - a largura das paginas, o espaço entre as linhas, a nitidez da impressão, as gravuras que ilustram o texto, foi tudo calculado e estudado, visando satisfazer as condições hygienicas necessárias em um livro escolar [...]” (p. IV). Como se pôde observar, Braga destacou a presença do texto visual como parte do objeto, e não como aspecto artístico da linguagem veiculada na obra.

No Livro III, a ideia de literatura foi ampliada e apresentou sinais da estética literária. Nessa obra, Braga incluiu a noção dos elementos estruturais da narrativa e os aspectos técnicos do poema: "separação das formas, prosa e verso" (p. III).

Além disso, o autor colocou em discussão o estudo de temas que integram uma cosmovisão patriota: "elementos physicos, da raça, de tradições, de influências estrangeiras e de personalidades que concorram para a constituição de nosso patrimônio intelectual” (p. III).

Pela primeira vez, surgiu a ideia de gêneros literários correspondentes ao universo infantil: "fabulas e apólogos, mythos e lendas, contos de fada e narrativas de fundo histórico." Entretanto, ainda vigorou na obra uma perspectiva utilitarista da literatura: "Predominam os elementos de estudo esthetico da expressão do pensamento, a par dos que entram na formação da consciência do direito e do dever. Intencionalmente, aqui e ali, ha apelos directos aos alunos, incitando-os a tirarem da narrativa suas ilações e a formularem juízo sobre o que leram" (p. III).

Ressaltamos também que a concepção de leitura esboça uma ampliação para os aspectos da linguagem literária. Braga afirma que o ato de ler serve para "formar imagens mentaes, pensar, interpretar, sentir" (p. IV).

No Livro IV, a ideia de literatura voltou-se para a preocupação com a edição do texto literário tendo em vista o propósito da leitura. Ao editor, cabe a responsabilidade de adequar os textos da Série para o público-leitor visualizado pelos publicadores:

[...] a revisão dos livros anteriores admitiu a simplificação do vocabulário, se não, por vezes, a alteração de períodos e frases. Já no presente volume que, sem ser propriamente uma antologia, recorre a excertos de nossos grandes escritores, os 
trechos teriam de ser respeitados em toda a sua integridade, tivessem sido escolhidos pela feição ou beleza do estilo, intenção humana que neles transpareça, ou ainda pela profunda significação cívica de que se achem iluminados. (BRAGA, p. III).

Além disso, Braga enfatizou a necessidade da mediação da leitura por parte do professor, sinalizando o entendimento de que a literatura infantil tem como alvo a formação do leitor literário.

Com relação à concepção de infância veiculada nos livros da Série, percebemos que a criança foi definida como um ser desprovido de cultura, o que exigiu uma adequação dos textos para essa realidade: "O estylo é simples, familiar, extreme, todavia, da preocupação de imitar a infantilidade de expressões comuns na linguagem das crianças, ou as formas dialectaes próprias do elemento inculto de nossa população" (p. IV).

Assim, levou-se em consideração a imaturidade intelectual do leitor para a composição da Série:

\begin{abstract}
Aqui, porém, o professor achará combinados elementos variados, que hão de corresponder, com certa amplitude, às modalidades do temperamento e tendências mentaes dos alunos dos cursos primários (p. III). O reflexo destes elementos na mentalidade dos alunos será grande, desde que no preparo da lição o professor os tenha em vista e os saiba empregar (p. V). [...] isso dará ao professor margem para fazer seleção dos trechos que melhor se adaptem à situação mental de seus discípulos [...]. (BRAGA, p. III e V).
\end{abstract}

Além disso, o autor definiu a criança a partir de sua relação com o professor. O leitor foi chamado de discípulo e também de patrício, e ao professor cabia "desenvolver no discípulo a faculdade da comparação e da analise de formas, aproveitando os fundamentos postos pelo ensino prévio pelo methodo analytico [...]" (BRAGA, p. IV- V).

Em decorrência disso, o alvo da Série foi a formação da ética e cidadania nos alunos: "o professorado que colabora na formação do espírito patriótico e na educação varonil de nossos jovens patrícios, fazendo propaganda do escotismo [...]” (BRAGA, p. V).

É certo que o autor também viu que a criança era detentora de ludismo, e há a necessidade de se oferecerem textos que trabalhem com esse aspecto do universo infantil:

[...] a orientação pedagógica que bane da escola as relíquias das emoções primitivas da alma humana, registradas nos mythos, nas fabulas e nos contos prodigiosos, é manifestação de um utilitarismo pernicioso em pedagogia. Ademais, revestem ellas realidades que o espírito da criança, instinctivamente descobre: a supremacia do bello sobre o torpe, a victoria da virtude sobre o vicio, a grandeza da integridade moral vencendo a baixeza da perfídia. (BRAGA, p. III).

A perspectiva utilitarista da literatura também se fez presente na concepção de infância, pois os livros de leitura marcaram época na primeira metade do século $\mathrm{XX}$, pelo fato de os 
alunos mais destacados nos estudos terem sido premiados ao final do ano letivo, em cerimônias festivas, com um exemplar do livro impresso.

Com relação ao aspecto religioso da Série, destaca-se que os livros manifestaram a temática religiosa por meio do ensino de educação moral e cívica. Esse tipo de educação era a intenção declarada pelo autor nos prefácios dos livros e também ficou subentendida no conteúdo dos textos selecionados.

O foco da educação era uma moral religiosa que se manifestava pelo bom comportamento, e isso, por sua vez, produziria um bem-estar social, uma convivência harmoniosa entre os homens, além de formar no leitor infantil o amor e orgulho pela pátria brasileira.

Como o nosso objeto de análise é o Livro I, seguiremos apresentando algumas características da obra em sua materialidade e, em seguida, procederemos considerando os elementos estruturais da narrativa.

A edição do Livro I analisada foi a de número 36-40. Essa edição é composta por 194 páginas, 69 capítulos, publicada pela Editora Melhoramentos de São Paulo e Rio (Weiszflog Irmãos Incorporado), com publicações nas cidades de São Paulo, Caieiras/SP, Rio de Janeiro e Recife.

No início da obra, já se observa a evidência da escola como uma instância legitimadora da obra, pois ela apresenta o seguinte texto: “Obra aprovada e adoptada pela directoria da instrucção publica dos estados de São Paulo, Paraná, Pernambuco, Ceará, Rio de Janeiro e do Districto Federal" (p. II).

Sobre o foco narrativo, no Livro I, percebemos o predomínio do narrador-personagem, em primeira pessoa na voz de um dos filhos. Esse tipo de narrador é coerente com a proposta da obra, uma vez que “[...] a narração em primeira pessoa costuma ser mais confiável que não confiável [...]" (WOOD, 2017, p. 18).

Trata-se de um narrador-testemunha ou "eu como testemunha": "testemunha, não é à toa esse nome: apela-se para o testemunho de alguém, quando se está em busca da verdade ou querendo fazer algo parecer como tal [...] o ângulo de visão é, necessariamente, mais limitado" (LEITE, 2007, p. 37). Na teoria de Jean Pouillon, trata-se de uma visão com, em que "o narrador limita-se a saber coisas sobre si e sobre os acontecimentos" (LEITE, 2007, p. 20). Leite ainda acrescenta que esse tipo de narrador está bem posicionado na narrativa e "narra de um ponto fixo, limitado quase que exclusivamente às suas percepções, pensamentos e sentimentos" 
(2007, p. 43). Portanto, a opção por esse ponto de vista é um dos elementos que viabiliza a natureza descritiva do texto.

A distribuição dos capítulos vai até o número 69, sendo que, desse total, 19 são textos de outros autores. Os textos selecionados por Braga se intercalam com a narrativa criada e composta pelo autor, conforme se vê no Quadro 1 abaixo:

Quadro 1 - Autores presentes no Livro I da Série Braga

\begin{tabular}{|l|l|}
\hline \multicolumn{1}{|c|}{ AUTORES E OBRAS } & CAPÍTULO DA SÉRIE BRAGA (LIVRO I) \\
\hline Thiago Pessanha & 3. O sonho de Joãozinho \\
\hline Tomás Antonio Gonzaga & 9. Belleza da vida campestre (Lira 19) \\
\hline Visconde do Araguaya & 11. O arbusto \\
\hline Francisco Villela e Marquez de Paranaguá & 12. Vida Feliz \\
\hline Felinto de Almeida & 14. Beija-flor \\
\hline Padre Sousa Caldas & 17. A creação \\
\hline Luiz de Camões & 19. A bonança \\
\hline Hilário Ribeiro & 29. Vozes dos animaes \\
\hline D. João Manuel & 35. A discreção \\
\hline Visconde de Taunay & 37. O sonho do sabiá \\
\hline Casimiro de Abreu & 38. Minha terra \\
\hline Gonçalves Dias & $\begin{array}{l}39 . \text { Canção do exílio } \\
4 . \text { Depois da tempestade }\end{array}$ \\
\hline João de Brito & 45. Anna Nery \\
\hline Belisario Penna & 46. Tres inimigos \\
\hline Barão de Paranapiacaba & 53. Fábula a cigarra e a formiga \\
\hline José Bonifácio & 56. O corneta da morte \\
\hline Visconde Pedra Branca & 58. Conselhos a Amelia (Lyra I) \\
\hline Joaquim José Teixeira & 62. O castigo (Idyllio II) \\
\hline
\end{tabular}

Fonte: Elaborado pelo autor.

Os textos desses autores, via de regra, são de natureza poética. Dentre os 69 capítulos do livro, 17 são de poesia e estão intercalados com a narrativa. De acordo com Braga, esses textos foram colocados, pois "tal é a correlação entre as passagens lidas anteriormente pelo alumno e os trechos em verso, que não haverá para o professor inteligente a menor dificuldade em fazelo embeber-lhe o espírito e a inspiração" (BRAGA, p. III). Com essa justaposição de narrativa 
e poesia, o autor entende que esta pode trabalhar a percepção do leitor bem como fertilizar a mente, o que passa a ser um aspecto positivo do livro.

Puccia (2005, p. 95) constatou que a incorporação de outros textos nos livros de leitura produzidos nas primeiras décadas do século XX era comum, pois havia "uma preocupação muito grande por parte dos autores em trazer o que de melhor conheciam de literatura universal para compor as páginas de seus livros [...] contribuindo de certa maneira, para a ampliação de sua cultura geral".

A presença de textos de outros autores no Livro I indica que Braga encontrou relações temáticas da narrativa com os poemas inseridos ao longo da narrativa. Trata-se de uma relação intertextual em que ocorre "um processo de incorporação de um texto em outro seja para reproduzir o sentido incorporado, seja para transformá-lo" (GUIMARÃES, 2009, p. 134). Assim, a intercalação dos textos poéticos na narrativa, em nosso entendimento, acaba por transformar o poema, uma vez que o sentido deste é determinado, a priori, pela narrativa. Isso "constitui uma resposta ao que foi dito ou, em termos de potencialidade, ao que ainda será dito, considerando que a intertextualidade encontra-se na base de constituição de todo e qualquer dizer" (KOCH; ELIAS, 2010, p. 101). E a resposta que se tem na junção dos textos está atrelada às intenções de formação moral e cívica, características do discurso predominante no Livro I.

Sabendo também que a intertextualidade diz respeito a uma "propriedade constitutiva de qualquer texto e o conjunto de relações explícitas ou implícitas que um texto ou um grupo de textos determinado mantém com outros textos" (DICIONÁRIO DE ANÁLISE DO DISCURSO, 2004, p. 288), é fundamental considerarmos que a relação entre a narrativa elaborada por Braga e os textos de outros autores é uma relação explícita.

É imprescindível que consideremos o que Marcuschi (2008) argumenta a respeito da distinção entre intertexto e intertextualidade, feita por Mangueneau. Nessa concepção, o intertexto diz respeito aos "fragmentos discursivos que aparecem e a intertextualidade seria o princípio geral que rege as formas de isso ocorrer" (MARCUSCHI, 2008, p. 130). Então, no Livro I, os trechos incorporados estão submissos aos valores pregados pela narrativa (formação moral e cívica, formação de leitores, e também aquisição de saberes).

Com relação ao enredo, a obra assume um tom predominantemente descritivo do espaço e das personagens e, portanto, não há uma trama caracterizada por introdução, desenvolvimento, clímax e desfecho. Assim, a obra não apresenta uma narrativa instigante em que o leitor é envolvido pelas surpresas da trama; o que há é uma constante apresentação descritiva dos espaços da narrativa com o intuito de informar o leitor a respeito dos assuntos 
veiculados no espaço em questão. O diagrama abaixo esboça a trajetória do Livro I no que concerne ao enredo:

Figura 1 - O enredo de Livro I

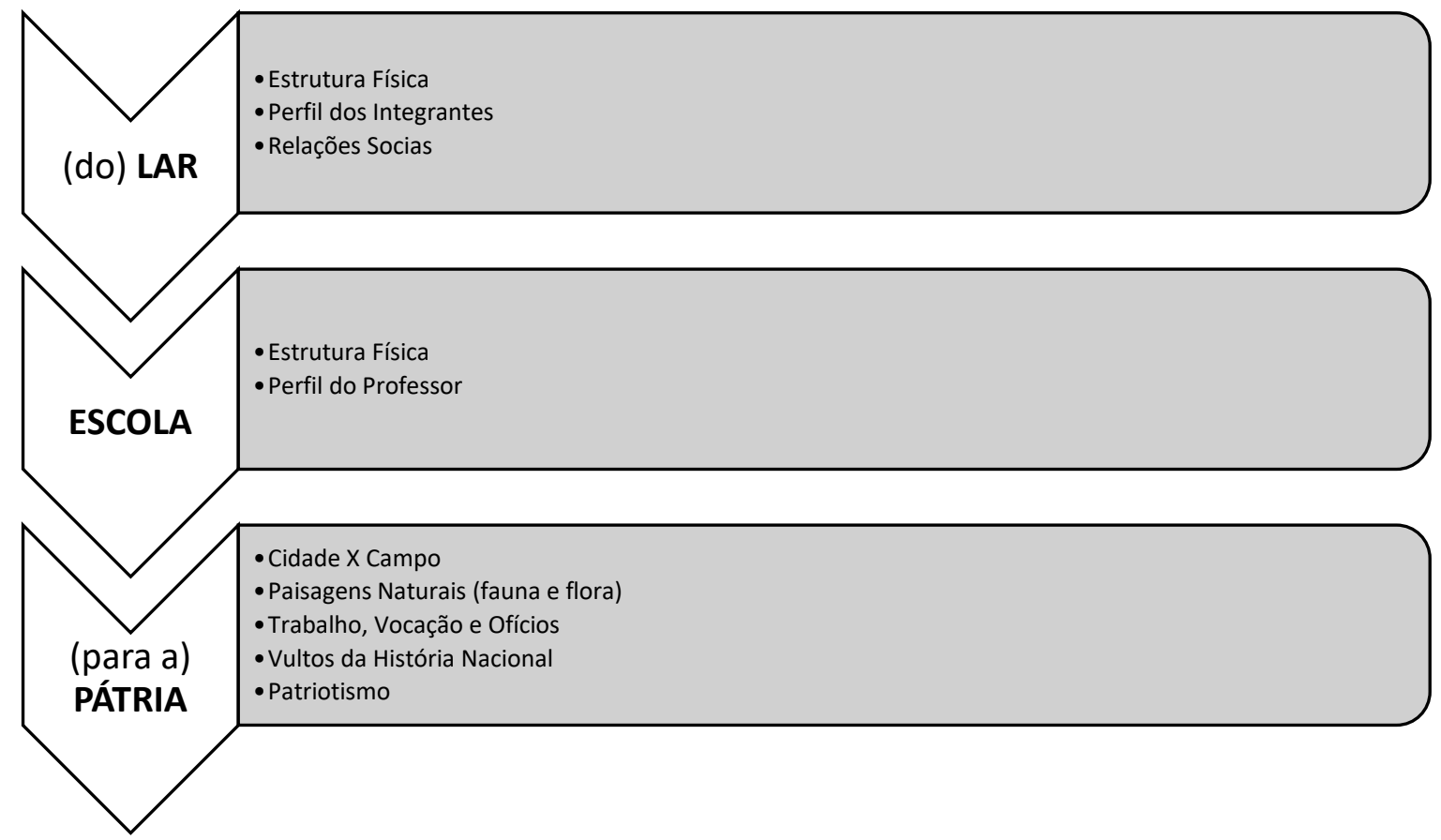

Fonte: Elaborado pelo autor.

Notamos que os espaços exercem um protagonismo na narrativa, pois eles delineiam ao leitor a trajetória esperada para um cidadão ideal no contexto do Brasil republicano do início do século XX, em que família e escola são instâncias fundamentais para a construção da pátria brasileira.

A trajetória lar - escola - nação faz da família um microcosmo do Brasil idealizado no contexto da obra, por isso, a história apresenta um padrão de personagens para cada um desses espaços, a começar pela família. A narrativa é gradativa na justaposição dos espaços, começando do menor elemento (lar) e terminando no maior, na perspectiva macro (pátria), tanto que, se partirmos do fim para o começo (nação-escola-lar), entendemos que a nação ideal tem 
na família a sua unidade mínima, e isso faz da escola um elemento de transição nesse processo gradativo.

O que se vê no Livro I é uma alternância entre espaço natural e espaço social. No espaço natural, as personagens ficam maravilhadas com a beleza da fauna e da flora brasileira, e, no espaço social, a ênfase recai sobre um padrão de sociedade coletivamente aceito e que necessita ser expandido para todo o território nacional. Nesse sentido, a sequência lar-escola-nação está coerente com a proposta.

Nesse aspecto, entendemos que o espaço exerce uma função pragmática. Para Coelho (2000, p. 78), a função pragmática do espaço ajuda "a caracterizar a personagem, a revelar sua atitude mental, seus costumes. Muitas vezes, o caráter da personagem é revelado em grande parte pela descrição do ambiente em que ela vive." É essa configuração de espaço que encontramos no Livro I.

Na configuração da família, temos a seguinte estrutura: os pais, que são apresentados pelo narrador como mamãe e papai; os filhos, sendo que Francisco "é o mais velho dos filhos, não é muito velho. Tem só onze anos" (BRAGA, p. 3), José "muito ativo e ajuizado, é mais moço que o Francisco." (BRAGA, p. 3), Amélia "é muito boazinha, muito graciosa e meiga." (BRAGA, p. 3), Joãosinho "o mais novo de todos, é um peralta de força", e Tio Carlos "ele estuda em uma escola muito longe. Volta, porém, para casa, nas férias” (BRAGA, p. 3). Há ainda os domésticos que são caracterizados da seguinte maneira:

[...] os criados são só domésticos. Eles recebem pagamento pelo serviço que prestam. São pessoas de confiança. Todas as pessoas da família os estimam [...] cada um tem sua obrigação: a cozinheira toma conta da cozinha; a Maria cuida dos arranjos da casa, e faz de copeira; o hortelão é que trabalha na horta e trata da chácara. (BRAGA, p. 6).

$\mathrm{Na}$ apresentação dos domésticos, o narrador enfatiza que eles são honrados pelo recebimento de salário e pelos serviços que prestam. Além disso, o narrador também destaca que ser um trabalhador é algo honroso, pois está pressuposto que ele possui caráter e inspira confiança.

Com relação aos membros da família, as ações das personagens são marcadas pelo bom comportamento e pela ética, o que aponta para valores ideais em uma família:

Todas as pessoas da família são muito amigas uma das outras [...] o Joãosinho é tão bonito e travesso que todos lhe acham graça [...] O Francisco, O José e a Amélia, que já mostram juízo, quando sabem que mamãe ou papai precisa de alguma coisa, vão correndo a ver quem os serve primeiro. (BRAGA, p. 4). 
É importante destacar a tônica da descrição das personagens. Pelo relato do narrador, percebemos ênfases de aspectos sociais, ideológicos e morais dos integrantes da família, caracterizando-os como personagens redondas. De acordo com Wood (2017, p. 22), as caracterizações sociais, ideológicas e morais se definem da seguinte maneira: social - "indicam classe social, profissão, atividades sociais"; ideológicas - "referem-se ao modo de pensar da personagem, sua filosofia de vida, suas opções política, sua religião."; morais - "se a personagem é boa ou má, honesta ou desonesta [...]”. Esses elementos das personagens ganham expressão à medida que os ambientes são descritos pelo narrador, e, assim, o lar, a escola, os ambientes da nação brasileira (cidade, campo, florestas, regiões, entre outros) delineiam o perfil das personagens para cada um desses espaços.

No Livro I, o espaço e ambiente são determinantes na configuração das personagens. Como a história começa no lar e termina na nação, a narrativa é contada de maneira que cada espaço evoca um perfil de personagem com determinadas características coerentes com o lugar apresentado. Isso é confirmado pela ideia de Osman Lins, ao tratar da questão do ambiente no espaço. Para ele, o ambiente é "o conjunto de processos conhecidos ou possíveis, destinados a provocar na narrativa a noção de um determinado ambiente” (LINS, 1976, p. 77). No Livro I, os processos utilizados são a descrição das virtudes das personagens manifestas em ações exemplares nos ambientes apresentados na narrativa.

Sobre o ambiente escolar, o Livro I aponta para as seguintes características: ela fica na cidade, lembra bastante o lar dos alunos, com um professor que é terno e bondoso, mostrandose sempre amigável. A escola é considerada uma extensão da família, e o narrador destaca que o "papai gosta muito delle" (BRAGA, p. 9), o que configura uma relação de reciprocidade entre os papéis socialmente exercidos.

Com relação ao espaço do Brasil, a história o segmenta nas seguintes temáticas: cidadesubúrbio-campo, flora e fauna, vocações e profissões, serviço à pátria. Esse itinerário revela os tópicos considerados essenciais para a construção da nação brasileira no contexto da república. É interessante observar que a temática da leitura e da contação de histórias estão presentes em dois capítulos da narrativa ( 22 - Em serviço da Pátria e 28 - Tio Carlos conta uma história), e cumpre-nos destacar alguns aspectos tanto da leitura bem como da importância das histórias nesses capítulos.

No capítulo 22, José começa a trabalhar para a nação brasileira ensinando o hortelão a ler e escrever, pois, até então, ele estava desprovido de conhecimentos fundamentais para a administração do seu negócio: "só faz contas com grãos de milho e riscos a carvão na parede, 
poderá fazer seus assentamentos em um caderninho" (BRAGA, p. 42). A leitura serviu para José ser destacado em seu serviço de professor, e para Manoel poder ser figurado entre os cidadãos cultos da nação por ocasião do recenseamento: "Quando o Manoel fizer o exame e for aprovado [...] terão de figura, no recenseamento, na columna dos que sabem ler e escrever" (BRAGA, p. 43). Então, o que se nota é que a leitura promove, por um lado, inserção social, mas, por outro lado, não se observa um trabalho com narrativa e imaginação.

No capítulo 28, temos a cena de uma contação de história por parte do tio Carlos. Estava chovendo e todos da família se reuniram para ouvir a história. Com relação à figura do contador, o texto descreve: “[...] ia conversando com os sobrinhos, sempre alegre, de bom humor, e pronto a ensinar aos que desejassem aprender" (BRAGA, p. 58). A postura do contador não indica nada de performance artística, pelo contrário, destaca que a contação está mais voltada para o campo do ensino do que para a arte, o que se aproxima da perspectiva clássica do contador de histórias.

E a história segue com metanarrativa ao reproduzir a história que o tio Carlos contou: "Era uma vez um dos generaes de Napoleão Bonaparte, no tempo em que era imperador dos francezes" (BRAGA, p. 58). A fórmula "era uma vez" aparece e sinaliza uma narrativa primordial. O que o tio conta às crianças é uma cena do General Dejean em que ele apanhava borboletas. Trata-se de uma cena de humor: "todos riram-se ouvindo contar a história de verdade [...]". Entretanto, o narrador enfatiza que esse acontecimento é real e, portanto, está confirmado pela História. Isso indica que o realismo tem proeminência sobre a ficção, e, embora as crianças tenham tido um momento de diversão com a narrativa, o que deve ser retido é a informação dada a respeito do passado.

Também julgamos importante considerar, nesta análise, a maneira pela qual a religiosidade se faz presente no Livro I. Do início ao fim, a temática da religiosidade não está explícita na obra, portanto não encontramos termos característicos da religião cristã católica ou protestante, tais como Deus, Jesus Cristo, Bíblia, entre outros. O único contato com a religião presente na obra está no capítulo 25 (A recepção).

Esse capítulo narra uma recepção que ocorreu na casa das personagens, e, nesse evento, a virtude da amizade é enfatizada. O narrador nos informa que, durante o evento, todos ficaram na sala entoando hinos de louvor à pátria, ao lar e à escola. E, além disso, a intimidade do lar é uma ligação espiritual que deve ser mantida por toda a vida. Esse ambiente de acolhimento e amizade é atribuído a um provérbio que está na entrada da casa: “o homem amável no trato será mais amigo que um irmão" (BRAGA, p. 51). No texto, esse provérbio é dado como sendo um 
provérbio antigo, entretanto ele tem fundamento no Livro de Provérbios, presente na Bíblia: "Em todo tempo ama o amigo e na angústia se faz o irmão" (Provérbios 17.7). É interessante notar que a referência à origem bíblica não é explícita, mas a ideia de amizade e amor que o texto veicula está presente no capítulo.

Feitas estas considerações, seguiremos para algumas inferências interpretativas com base nos pontos destacados na análise do Livro I.

O primeiro aspecto de nossa interpretação é o mérito da obra em justapor o texto narrativo com o texto poético. Por mais que a obra tenha, assumidamente, um caráter pedagógico sobreposto ao literário, entendemos que a poesia tem valor em si para aguçar a percepção do leitor para a estética. Mais do que memorização (o que é importante), a poesia tem em sua natureza a potência para a fertilização da imaginação na medida em que articula palavra, imagem e som. Tal experiência com o texto é sempre benéfica e prazerosa, via de regra.

O segundo aspecto a ser pontuado é o fato de que o Livro I está coerente com as propostas que vigoravam no contexto da primeira metade do século XX. Os livros de leitura mostram que leitura e escola sempre caminharam juntas, pois foi para a escola que se atribuiu a responsabilidade da formação do leitor: "a escola, através do processo de alfabetização e de dinâmicas de letramento, é a principal agência responsável pelo adentramento - e talvez permanência - das pessoas no mundo da escrita" (SILVA, 2012, p. 109). Por isso, por meio da leitura dessa obra, constatamos que a produção de livros de leitura para o ambiente escolar fez da escola um espaço de formação, desenvolvimento e ação de leitores. Entretanto, vale destacar também que a literatura foi um meio nesse processo educativo e, portanto, pragmático.

O terceiro aspecto a ser pontuado diz respeito à natureza descritiva do Livro I. Pelo fato de priorizar os espaços (lar, escola e pátria) na narrativa, houve a necessidade de subordinar o texto narrativo ao texto descritivo. Em nosso entendimento, essa característica enfraquece a narrativa, uma vez que esta fica desprovida da sequência característica de uma trama (introdução, desenvolvimento, clímax, desfecho).

Em decorrência desse aspecto, podemos inferir também que o objetivo da produção do texto foi, principalmente, a formação do leitor, de um lado, no aspecto civil e moral, e, de outro, no aspecto da aquisição de saberes envolvendo geografia, ofícios e história do Brasil.

Isso nos faz considerar também que o Livro I é um produto-tipo de uma época em que os livros que circulavam no contexto escolar eram marcados pelo nacionalismo com a valorização da paisagem e da língua brasileira. Por isso, no Livro I, notamos a ausência de fantasia e imaginação, e o predomínio de realismos. 
A formação de um leitor literário decorria do trabalho com dados a respeito da realidade nacional. Essa escolha do conteúdo veiculado nas obras evidencia que era o adulto que falava pela criança justamente pelo fato de que as informações do texto estavam arquitetadas de forma prescritiva, com o intuito de se formar uma criança padrão para o Brasil republicano.

Se levarmos em consideração os pressupostos teóricos elencados neste artigo, podemos fazer um paralelo entre as considerações a respeito da educação literária e a proposta de formação do leitor veiculadas no Livro I. A educação literária ${ }^{1}$ volta-se para a formação estética do leitor e, para isso, leva em consideração a natureza do texto literário, a relação literatura e leitor e a experiência do leitor com o texto. O diagrama abaixo ilustra a aproximação desses dois paradigmas de formação do leitor literário:

Figura 2 - Educação Literária e Livro I

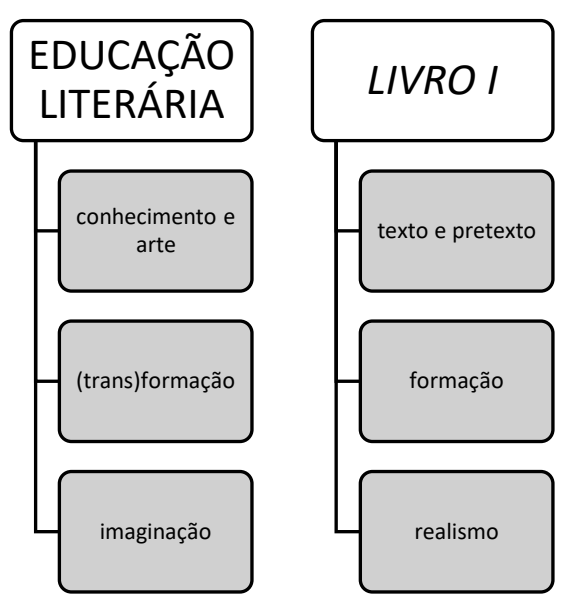

Fonte: Elaborado pelo autor.

Notemos que a ideia de texto como pretexto no Livro I significa que o texto está a serviço de um ideal ou sendo usado de forma pragmática. Entretanto, na perspectiva da educação literária, o texto é uma obra de arte que deve conduzir o leitor a um gosto acurado para a recepção do belo.

Diante dessas considerações, podemos concluir que, no Livro I, a formação do leitor voltou-se mais à promoção das virtudes do que à formação do gosto pela leitura e pela ficção. Por isso, a obra analisada configura-se mais como um manual de virtudes e bons costumes do que como uma obra de ficção.

\footnotetext{
${ }^{1} \mathrm{O}$ conceito de educação literária remete ao da inter-relação entre as concepções de literatura como arte e os aspectos inerentes ao leitor, tais como: acesso à obra, prazer e gosto e experiência com a recepção da obra. Essa investigação foi realizada em outro estudo que está em fase de publicação sob o título EDUCAÇÃO LITERÁRIA: do texto à experiência (trans)formadora do leitor.
} 


\section{Considerações Finais}

Um dos objetivos de se ter feito esta investigação histórica foi justamente a captação de subsídios para a avaliação da trajetória bem como para a avaliação dos caminhos da leitura literária na escola desde a primeira metade do século XX. Por isso, podemos elencar algumas considerações.

Levando em consideração o corpus analisado neste artigo, sinalizam-se temas que estiveram presentes na educação tais como: família, escola e pátria. Notemos que, por meio da análise, esses temas são apresentados como mantendo uma interface entre si. Entendemos, na análise, que a família foi vista como um microcosmo do Brasil, e a nação brasileira teve como semente a família no contexto republicano. A escola foi colocada como o elemento intermediário que serviu de extensão da família e que teve a missão de preparar cidadãos para a república que se formava nas primeiras décadas do século XX.

No contexto escolar, coube à escola formar leitores na perspectiva da cidadania mais do que na percepção e recepção da arte da palavra e da imagem. Por isso, a narrativa do Livro I colocou o espaço como o revelador das virtudes necessárias às personagens da história.

É fundamental considerar também a realidade do mercado consumidor de livros escolares. Como vimos, a Série Braga ultrapassou o número de 100 edições (o que foi comum a muitos livros de leitura dessa época). Então, sendo o livro de leitura um antecessor do livro didático, percebemos que esse segmento sempre fez parte das atividades de leitura na escola e alavancou a produção das casas publicadoras, produção esta que foi marcada por obras que veiculavam temáticas que iam de encontro a expectativas do governo para a escola.

Um indicativo disso é a expressão que consta no corpus (já citada) “obra aprovada e adoptada pela directoria da instrucção publica dos estados de São Paulo, Paraná, Pernambuco, Ceará, Rio de Janeiro e do Districto Federal.” Tal expressão sinaliza um relacionamento firmado entre governo, casa publicadora e secretarias de educação dos estados citados no texto. Por meio desses dados, identificamos também que o governo sempre foi um comprador dos livros que seriam utilizados no contexto escolar desde os primeiros momentos da literatura infantil, e isso tem se mostrado como um fator condicionante dos conteúdos para que o produto atenda às expectativas do comprador.

\section{Referências}

ARROYO, Leonardo. Literatura infantil brasileira. 3. ed., São Paulo: Unesp, 2011. 
COELHO, Nelly Novaes. Panorama histórico da literatura infantil e juvenil. Das origens indo-europeias ao Brasil contemporâneo. 5. ed., Barueri/SP: Manole, 2010.

COELHO, Nelly Novaes. Literatura infantil: teoria, análise, didática. São Paulo: Moderna, 2000.

COLOMER, Teresa. Andar entre livros: a leitura literária na escola. São Paulo: Global, 2007.

DICIONÁRIO DE ANÁLISE DO DISCURSO. São Paulo: Contexto, 2004.

GUIMARÃES, Elisa. Texto, discurso e ensino. São Paulo: Contexto, 2009.

KOCH, Ingedore Villaça; ELIAS, Vanda Maria. Ler e escrever: estratégias de produção textual. 2. ed., São Paulo: Contexto, 2010.

PUCCIA, S. O livro de leitura (1889-1933) Instrumento de Educação e Instrução. Quaestio Revista de Estudos em Educação, v. 5, n. 2, 11 (2003).

LAJOLO, Marisa; ZILBERMAN, Regina. Literatura infantil brasileira. História e Histórias. 6. ed., São Paulo: Ática, 2010.

LEITE, Ligia Chiapini Moraes. O foco narrativo. 11. ed., São Paulo: Ática, 2007.

LEITE, Miriam L M. A infância no século XIX segundo memórias e livros de viagem. In:

História social da infância no Brasil. 3. ed., São Paulo: Cortez, 2001.

LINS, Osman. Lima Barreto e o espaço romanesco. São Paulo: Ática, 1976.

MARCUSCHI, Luiz Antonio. Produção textual, análise de gêneros e compreensão. São Paulo: Parábola Editorial, 2008.

MEAD, Margaret. L'adolescente in una società primitiva. Firenze: Ed. Universitária, 1968.

MONARCHA, Carlos. Arquitetura escolar republicana: a escola normal da praça e a construção de uma imagem de criança. In: História social da infância no Brasil. 3.ed., são Paulo: Cortez, 2001.

OLIVEIRA, C. R.G. A.; SOUZA R. F. As faces do livro de leitura. Cadernos Centro de Estudos Educação e Sociedade (CEDES), n 52, novembro, 2000. Disponível em: $<$ https://repositorio.unesp.br/bitstream/handle/11449/28247/S010132622000000300003.pdf; sequence $=1>$. Acesso em: 14/11/2019.

SILVA, Ezequiel Theodo. A escola e a formação de leitores. In: Retratos da leitura no Brasil. 3. São Paulo: Imprensa Oficial do Estado de São Paulo/Instituto Pró-livro, 2012.

VERÍSSIMO, José. A educação nacional. 2.ed., Rio de Janeiro: Livraria Francisco Alves, 1906. 
WOOD, James. Como funciona a ficção. São Paulo: Sesi, 2017.

ZILBERMAN, Regina. Literatura infantil na escola. 11. ed., São Paulo: Global, 2003.

\section{Livros da Série Braga}

BRAGA, Erasmo. Série Braga - Leitura I. 40. ed., São Paulo: Melhoramentos, s/a.

BRAGA, Erasmo. Série Braga - Leitura II. 70. ed., São Paulo: Melhoramentos, s/a.

BRAGA, Erasmo. Série Braga - Leitura III. 35. ed., São Paulo: Melhoramentos, s/a.

BRAGA, Erasmo. Série Braga - Leitura IV. 103. ed., São Paulo: Melhoramentos: 1953.

Recebido em: 18/05/2020

Aceito para publicação em: 29/09/2020 